\author{
Alban Denys \\ Patrick Chevallier \\ Francesco Doenz \\ Salah D. Qanadli \\ Daniel Sommacale \\ Michel Gillet \\ Pierre Schnyder \\ Bertrand Bessoud
}

\section{Interventional radiology in the management of complications after liver transplantation}

Received: 27 January 2003

Revised: 17 September 2003

Accepted: 18 November 2003

Published online: 9 January 2004

(C) Springer-Verlag 2004

A. Denys $(\bullet) \cdot$ P. Chevallier $\cdot$ F. Doenz

S. D. Qanadli · P. Schnyder · B. Bessoud Department of Radiology and Interventional Radiology,

Centre Hospitalier Universitaire Vaudois, 1011 Lausanne, Switzerland

e-mail: Alban.Denys@chuv.hospvd.ch

Tel.: +41-21-3144470

Fax: +41-21-3144443

D. Sommacale

Department of Digestive Surgery,

Hospital Beaujon, Clichy, France

M. Gillet

Department of Digestive Surgery

and Transplantation,

Centre Hospitalier Universitaire Vaudois,

Lausanne, Switzerland

\begin{abstract}
The arrival of new surgical transplantation techniques, such as split living donor or auxiliary liver transplantation, have increased the incidence of vascular and biliary complications. The causes, symptoms, and diagnostic modalities of arterial, portal caval, and biliary complications are detailed. Interventional techniques, such as balloon angioplasty and stent placement in the arterial and portal tree, as well as biliary interventional techniques, are discussed.
\end{abstract}

Keywords Liver transplantation . Hepatic artery $\cdot$ Portal vein · Inferior vena cava $\cdot$ Biliary tree . Interventional radiology

\section{Introduction}

Liver transplantation is now widely accepted as the goldstandard treatment of advanced chronic liver disease, acute liver failure, and of some metabolic liver disorders. During the past 10 years, improvements in immunosuppressive techniques, as well as sophisticated surgical techniques, have improved patients' short- and long-term survivals. According to the United Network of Organ Sharing (UNOS) 2000 report, 26,652 liver transplants were performed in the United States from 1990 to 1998 with 1- and 5-year survival rates of 87 and $74 \%$, respectively [1]. Actuarial 1-, 5-, and 10-year survival rates were 79,67 , and $57 \%$, respectively, in a recent publication of over 4000 transplantations [2]. The time period associated with the highest risk of mortality is the first year after transplantation particularly in the first 3 months due to graft dysfunction, technical problems due to vascular and/or biliary complications and infections [3]. In a context of organ shortage, interventional radiology is used to manage vascular and biliary complications in order to avoid retransplantation or to provide a bridge until a suitable donor is available. In the most recent surgical techniques, such as split liver transplant, living donor transplantation or auxiliary transplantation, the incidence of vascular and biliary complications increases with the surgical complexity.

The aim of our article is to review the different strategies and techniques available in interventional radiology for the treatment of these complications. 


\section{Arterial complications}

In liver transplant, liver receives oxygen both from the portal vein and the hepatic artery; however, the biliary tree is fed only by the hepatic artery as a contrary to native liver where very rich arterial network coming from choledochal branches originating from the posterior pancreatico-duodenal arcade but also from the capsular branches protect the biliary tree from ischemia. This is why the patency of hepatic arterial vessels are of crucial importance after liver transplantation. Arterial complications can be divided into early arterial thrombosis occurring in the first month after transplantation, late arterial thrombosis occurring after this delay, hepatic artery stenosis, and steal syndrome from the splenic or gastroduodenal artery. Recent publications report a rate of hepatic artery thrombosis of $6.8 \%$, one-third in the first month after transplantation and two-thirds after this delay [4]. A similar amount of hepatic artery stenosis is reported [5]. Factors associated with hepatic artery stenosis and thrombosis are numerous. Risk is increased in children particularly in infants under 12 months [6]. Technical problems related to a small recipient, retransplantation, arterial anastomosis to an old conduit, and reconstruction of anatomic variation of the donor hepatic artery may be responsible. Other factors, such as recipient negative cytomegalovirus status, biopsy proven rejection in the first week, combination of female donor and male recipient have also been advocated $[4,7,8]$.

Hepatic artery steal syndrome from the splenic or gastro-duodenal artery is a more recently studied entity. It is defined by a decreased perfusion in the hepatic artery due to a diverted blood flow either in a large splenic or gastroduodenal artery. While it is found in $5.9 \%$ of patients, its role in the liver ischemia is still debated. Furthermore, its treatment remains complex, with a high rate of complications a after splenic ligation or embolization requiring re-transplantation in 18\% of cases [9].

Clinical presentation of hepatic arterial occlusion is variable and depend of many factors. The delay of arterial complication is of critical importance. Hepatic artery thrombosis occurring in the first month may have a mortality rate as high as $55 \%$, whereas it decreases to $15 \%$ if thrombosis occurs after this period [4]. The age of the patients is also very important. In children, hepatic artery complications are more frequent but are claimed to have less consequence mainly in they occur late after transplantation. Probably children have more facilities to revascularize the liver through all the adhesions of the graft to the diaphragm, and other adjacent organs [10]. In adults, even in the late phase after transplantation, hepatic artery occlusion may induce severe biliary complications such as biliary necrosis, biliary leak or liver abscesses $[11,12]$. The range of clinical symptoms goes from acute liver failure and death to biliary anastomotic stenosis. But most of clinical and biological symptoms are related to the biliary tree. Biliary ischemia may have very discrete presentation limited to anastomotic stenosis or leak. But ischemia may have disastrous consequence with diffuse biliary lesions associating stenosis and cast formations made of endothelial desquamations [13].

The role of Doppler US is of critical importance in the follow-up of transplanted patients. Hepatic artery stenosis or thrombosis should be depicted as soon as possible. Doppler studies must be repeated very frequently in the early post-operative period, even every day as long as the patient is still in the hospital [14]. Thereafter, it should be done in a repeated fashion, even if patient has no clinical or biological symptoms. Diagnostic performance of sonographic studies are good if the method is adequate. Exploration of the right, left, and common hepatic artery must be done. Doppler curves must be registered and resistive index and systolic ascending time calculated. A resistive index below 0.5 and a systolic ascending time superior to $8 \mathrm{~ms}$ corresponding to the socalled tardus-parvus wave form have an excellent sensitivity for hepatic artery stenosis [15]. In the pediatric population, Doppler false-negative cases with normal wave forms and hepatic artery occlusions were demonstrated due to the development of arterial collaterals [10]. In the adult population, the rate of false-negative cases ranges from 3 to $19 \%[15,16]$. Recent developments, such as contrast-enhanced US, may improve these results in the near future [17].

Treatment options for symptomatic hepatic artery thrombosis are surgical revascularization in the early phase or retransplantation $[4,7,8]$. Endovascular treatment of hepatic artery thrombosis has been recently reported in case reports or small series in the early phase after transplantation $[18,19,20]$. Despite the risk of bleeding due to the post-operative periods, these authors used fibrinolytic therapy followed by balloon angioplasty or stent placement. There is no severe complication reported by these authors using this technique.

Treatment of hepatic artery stenosis is more debated because a higher number of patients are asymptomatic at the moment of the diagnosis. Arguments for the treatment are numerous. Firstly, it has been demonstrated that stenosis may evolve to hepatic thrombosis even though one case demonstrated spontaneous resolution [21]. Secondly, symptom improvement and liver-test amelioration have been demonstrated after stenosis correction [20, 22, 23, 24, 25, 26]. Thirdly, Abbasoglu et al. [5] reviewed survival and graft patency of patients with hepatic artery stenosis after transplantation, and they discovered that hepatic artery stenosis, if not treated, double the rate of biliary complications known to reduce life and graft expectancy. This was also observed by Orons et al. who found a $67 \%$ incidence of biliary abnormalities in patients with hepatic artery stenosis as compared with $11 \%$ in control group [27]. Finally, Abbasoglu et al. [5] demonstrated also that patients with hepatic artery stenosis 


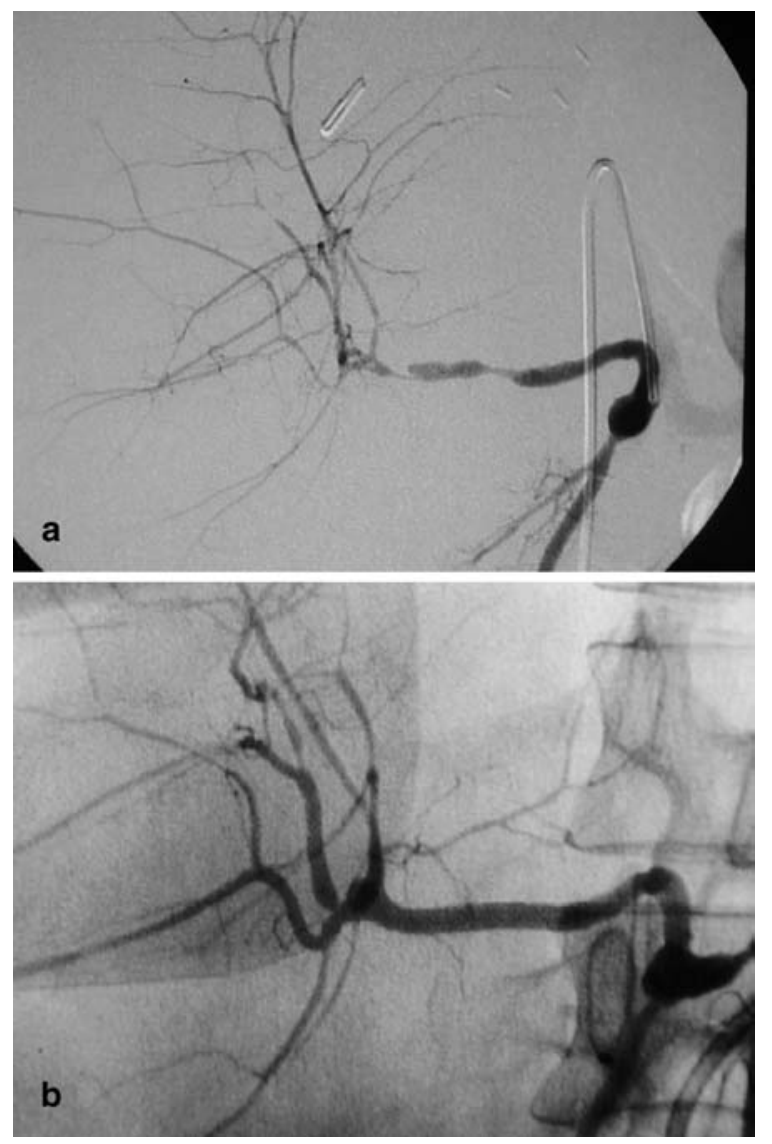

Fig. 1a, b A 45-year-old patient received a right hepatic lobe from a cadaveric donor. An elevated transaminase level, as well as an abnormal US Doppler study, suspected arterial stenosis in the first hours after transplantation. a A celiac angiogram shows a long dissection of the right hepatic artery downstream of the anastomosis. b A coronary stent is implanted using a monorail technique and allows a complete restoration of the hepatic arterial flow with a normal angiogram

treated by means of surgical or radiological procedures, whether or not they are symptomatic when they have been diagnosed, have the same graft and life expectancy than patients with patent hepatic artery. Different treatment have been proposed such as surgical reconstruction using various protocols (end-to-end anastomosis up to graft interposition), or percutaneous methods. Percutaneous balloon dilatation has been proposed a few years ago [23]. From this first publication using 5-F balloon catheters, technical improvements, such as monorail material, 0.014-in. guide wires, guiding catheter, and stents derived from the cardiological field has allowed to treat more complex lesions such as dissection, occlusion or stenoses occurring in very tortuous vessels (Fig. 1) [20, 22].

From the different series (Table 1), biological and clinical improvements have been described after hepatic artery stenosis endovascular treatment $[20,22,24,26$, 28]; however, some patients do not improve or even continue to worsen after correction. From the literature there are no criteria to decide who will benefit or not from this treatment. Restenosis has also been demonstrated after endovascular treatment both at the treated site and at other locations [22]. Series are difficult to compare, and since the follow-up technique does rarely include the gold standard angiography [22], Doppler is more commonly used but carries the risk of false-negative results.

\section{Portal complications}

The rate of portal complications in orthotopic transplantation has been reported to be very low. In a large review of 393 consecutive orthotopic liver transplantations, the rate of post-transplantation portal thrombosis was found in $1.8 \%$ of cases despite previous recipient portal vein abnormalities found in $16.3 \%$ of cases (including portal vein thrombosis, sclerosis, and hypoplasia) [29]. In these series, factors that increased the risk of portal vein complications were a pre-existing portal vein thrombosis or hypoplasia and large porto-caval collateral. Porto-portal anastomosis stenosis or thrombosis may be silent if large porto-portal collateral develop in the liver hilum, but in most cases symptoms of portal hypertension reoccur in that situation [30].

This situation has changed with the development of both pediatric liver transplantation and with the use of reduced-size liver transplant and by living-relative transplant using segments II and III from a living-relative donor. The portal vein anastomosis is technically challeng-

Table 1 Review of the main studies reporting balloon angioplasty treatment, hepatic artery stenosis, or thrombosis. $B A$ balloon angioplasty, $S$ stent

\begin{tabular}{|c|c|c|c|c|c|c|}
\hline Reference & No. of patients & Technique & $\begin{array}{l}\text { Technical success } \\
(\%)\end{array}$ & $\begin{array}{l}\text { Complication rate } \\
(\%)\end{array}$ & $\begin{array}{l}\text { Retransplantation rate } \\
(\%)\end{array}$ & $\begin{array}{l}\text { Follow-up } \\
\text { (months) }\end{array}$ \\
\hline [61] & 7 & BA & 100 & $?$ & 14 & $?$ \\
\hline [5] & 6 & $\mathrm{BA}$ & 100 & 0 & 0 & 26 \\
\hline [25] & 19 & BA & 81 & 10 & 38 & $?$ \\
\hline [20] & 4 & $\mathrm{~S}$ & 100 & 0 & 0 & $18-25$ \\
\hline [22] & 13 & $\mathrm{~S}$ & 92 & 8 & 0 & 24 \\
\hline
\end{tabular}


Fig. 2a-d A 45-year-old patient suffers from recurrent variceal bleeding 3 months after orthotopic liver transplantation (OLT). a Contrastenhanced CT at the level of the liver hilum demonstrates small intra-hepatic branches associated with periportal edema. b Portography performed by a trans-hepatic route shows complete obstruction of the portal vein in the hilum. c After recanalization, angiogram performed upstream shows dilated superior mesenteric vein and revers-ed inferior mesenteric vein. d After stent placement, the flow is now rerouted in the recanalyzed portal vein. Note that the inferior mesenteric vein is no longer reversed
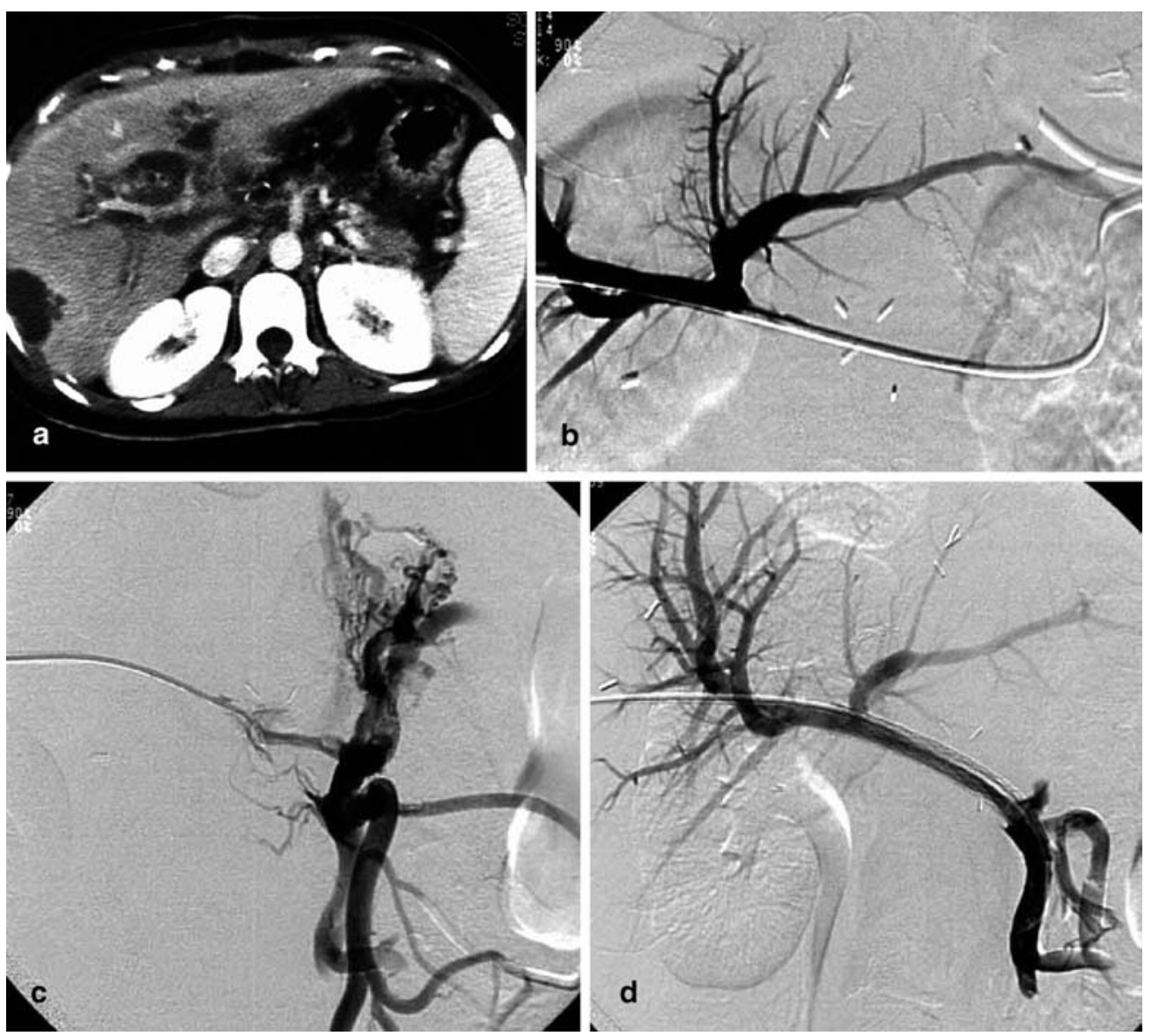

ing since the graft portal venous segment is short and necessitates the use of interposition graft. These grafts increase significantly the risk of portal vein complication [31]. Diagnosis of portal vein stenosis can be achieved in pediatric patient by US Doppler when the portal vein diameter is below $2.5 \mathrm{~mm}$ in diameter and a when a jet flow is visible in color Doppler at the stenotic site [32]. In adult population, the criteria are a corrected velocity superior to $1 \mathrm{~m} / \mathrm{s}$ or threefold of the velocity upstream in the portal vein [33].

Endovascular techniques by balloon venoplasty have been proposed since 1991 for portal vein stenoses [26]. Since that early publication, more than 40 cases have been reported, most of them being pediatric cases [26, $34,35,36,37,38]$. The method consists of a percutaneous approach of a portal branch in the liver, whereas transjugular approach has been reported by some authors [39]. The right approach is preferred in case of full-size liver graft because of a more straight approach to the anastomotic site. In case of reduced liver, a left portal branch is punctured. A balloon is inflated on the stenotic site after pressure measurement across the stenosis. If portography is satisfactory after the procedure, or if the gradient is below $5 \mathrm{~mm} / \mathrm{Hg}$, then the procedure is fin- ished. If there is a recoil or if the pressure gradient is higher than $5 \mathrm{~mm}$, a stent is implanted across the stenosis. The long-term patency in the study of Funaki et al. [36] shows that stenosis reccurred after a mean followup of 6.3 months in $50 \%$ of balloon venoplasty. Stent patency showed to be excellent with a $100 \%$ patency rate after 47 months of mean follow-up (Fig. 2). Symptoms disappeared completely in all cases where the treatment could be done. Cases of portal vein occlusions have also been treated by a combination of chemical thrombolysis and stent placement with a good success $[40,41]$. The use of mechanical fragmentation have also been reported [41].

\section{Caval complications}

Of all vascular complications occurring after orthotopic liver transplantation (OLT), caval complication is the most rare accounting for less than $1 \%$ of patients [42]. The "piggyback" technique is the most commonly used technique since it preserves the inferior vena cava and carries a low rate of complications [43]. In living-relative and other partial liver reconstruction, the rate of 
Fig. 3a-c A 56-year-old woman was readmitted for persistent medicoresistant ascitis 1 month after OLT. a Hepatic phlebography and pressuregradient measurement shows stenosis of the cavo-caval anastomosis with a high-pressure gradient. b After stent placement, the gradient has disappeared. $\mathbf{c}$ Ultrasound of the hepatic vein ending demonstrates a patent stent over the stenosis 3 years after treatment
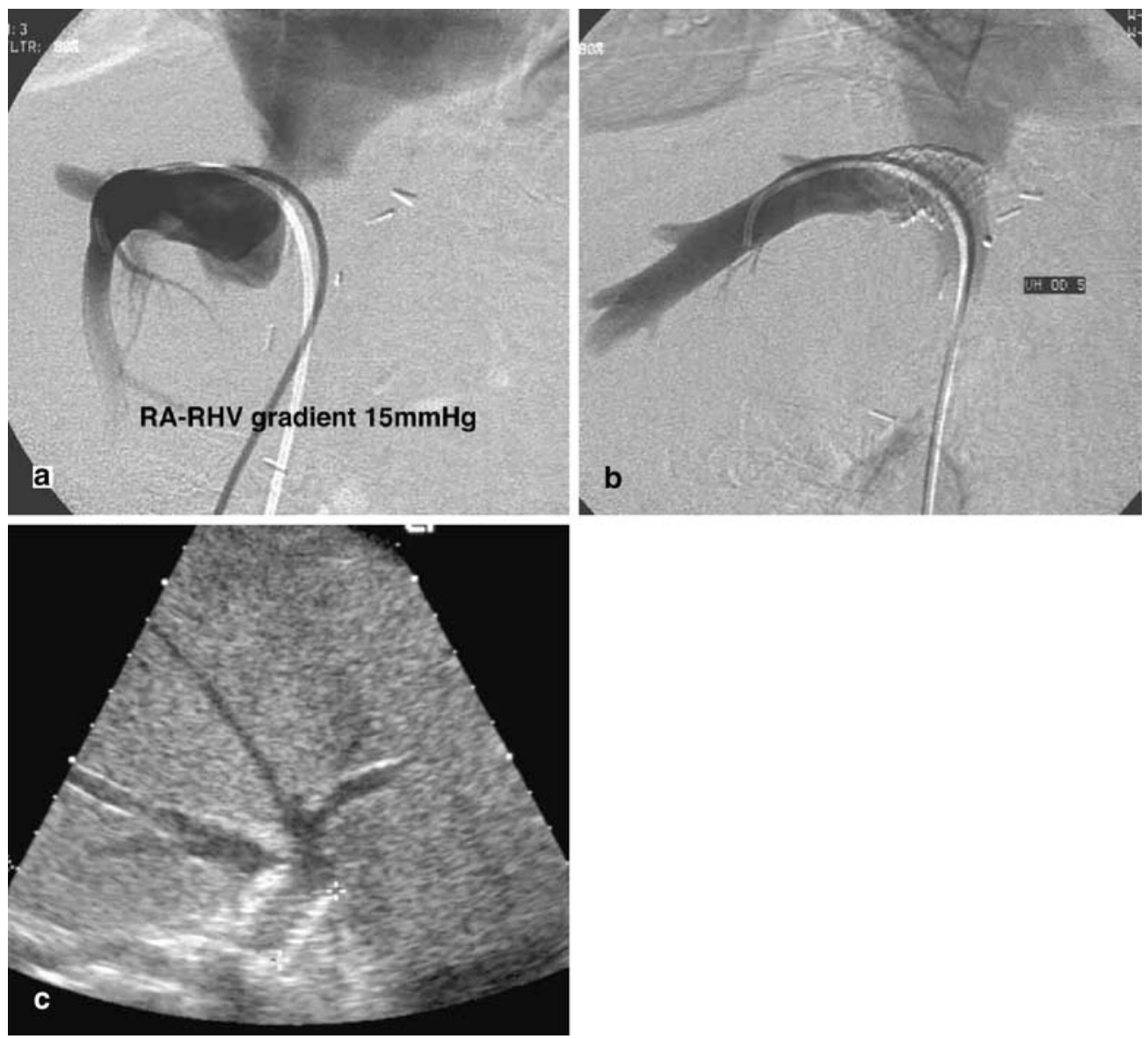

venous outflow obstruction is higher and reported in up to $3.9 \%$ [44]. Hepatic outflow obstruction can be related either to a preexistent venous disease, such as in patients with Budd-Chiari syndrome, or in children with biliary atresia. Surgeons there need to perform atypical caval anastomosis which are more prone to delayed complication. The other category is venous anastomotic stricture. Symptoms are similar to a Budd-Chiari syndrome with ascitis and graft failure. This complication can be recognized with certain delay, because in patients who were transplanted for chronic liver disease and ascitis, ascitis can persist for a few weeks after OLT and preclude diagnosis of venous complication.

Diagnosis of these complications is usually done by means of Doppler studies. In these cases, thrombosis of the hepatic vein can be found but more frequently a slow demodulated flow in found in the hepatic veins. Stenotic site can also be found using Doppler sonographic study.

Endovascular repair is preferred by transplantation team because surgical repair is complex and necessitates complete dissection of the graft and even a transdiaphragmatic route. Technique of endovascular repair consist in catheterism of the venous stenosis. Depending on Doppler result, femoral or jugular route will be chosen. We prefer to use a femoral approach in case of side-to-side caval anastomosis. In case of end to side or in case of cavoatrial anastomosis, a jugular approach is more convenient. The procedure is usually performed under local anesthesia. After catheterism, pressure measurement is mandatory to confirm hemodynamic consequence of the stenosis. A gradient $>5-6 \mathrm{~mm} / \mathrm{Hg}$ is usually considered to be sufficient to induce symptoms [45]. In most series as in our experience, the use of stent is almost systematic (Fig. 3) because of the fibrous nature of surrounding tissue leading to immediate recoil after balloon angioplasty [35, 42, 45]. We used balloon expandable stents in this situation which offers two advantages in case of hepatic venous outflow obstruction. Their placement may be very precise, and they can be redilated, if mandatory, according to gradient measurements.

Inferior vena cava syndrome can be observed in the early post-operative period because of compression of the inferior vena cava by the graft in case of small recipients or due to torsion of the inferior vena cava. These symptoms can be alleviated by insertion of Gianturco stents in the inferior vena cava [46]. 
Fig. 4a-c A 48-year-old patient transplanted 6 months previously is readmitted for recurrent jaundice episode. a Plain CT demonstrates hyperdense material within the biliary confluence. b Percutaneous cholangiography demonstrates no dilatation of the intrahepatic bile duct despite the filling of the biliary confluence by occlusive casts associated with a stenosis of the biliary anastomosis. c Cholangiogram obtained 1 year later
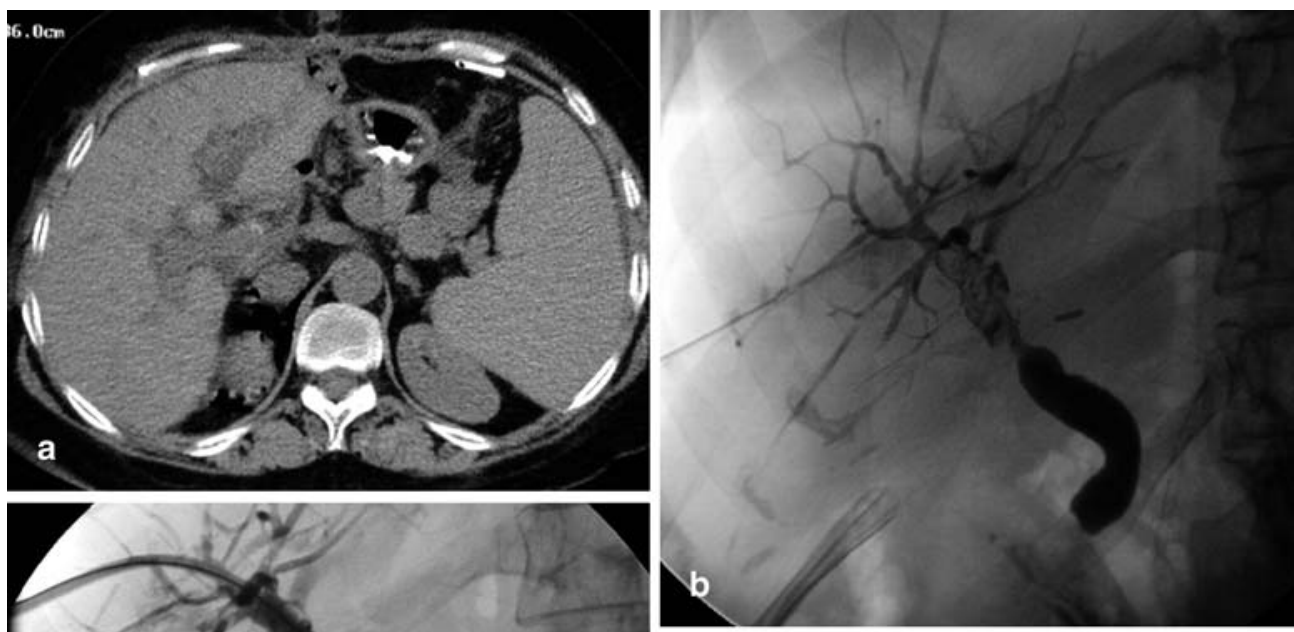

\section{Biliary complications}

Biliary complications of some type occur in between 10 and $25 \%$ of liver transplantations $[13,47,48]$. This frequency is increased up to $25 \%$ in case of recipients of reduced-size grafts because segmental biliary anastomosis by hepatico-jejunostomy must be carried out in number of patients [49]. The vast majority appear within the first 3 months. Approximately half of them are involving only the anastomotic site and consist of bile leaks and anastomotic strictures. Virtually, all these early complications have a technical origin related to an ischemic necrosis of the end of the bile duct or a technically unsatisfactory anastomosis. The presence of a T-tube does not seem to reduce this rate of complications [50]. Stenosis are amenable to percutaneous drainage using large-bore catheters endoscopic drainage with good long-term success (Fig. 4) [51, 52]. Basic technique consists of a initial balloon biliopasty followed by long-term drainage, either endoscopic or percutaneous, during 1 year with frequent changes of drains or stents to avoid silent occlusions [51]. Duration of the long-term drainage is variable from one center to another, some choose to drain only during a short period of time after bilioplasty, but it requires more frequent treatment sessions (from one to three sessions) [53]. The success rate is approximately $70-80 \%$ in both endoscopic and percutaneous series and the rate of complications is similar $(5-8 \%)$. To our knowledge, there is no randomized study comparing per- cutaneous to endoscopic approach in those indications. The use of partial liver transplantation increases the rate of hepaticojejunostomy. As a consequence, anastomotic stenoses are treated percutaneously since it could not be reached endoscopically.

Management of leaks requires antibiotherapy, bilioma drainage, and biliary drainage. Biliary leaks related to a $\mathrm{T}$ tube or to a cystic duct are managed successfully from a percutaneous or endoscopic approach in most cases. On the other hand, anastomotic leaks related to biliary necrosis at the anastomotic site tend to respond less to non-operative management and require a Roux-in-Y anastomosis in $33 \%$ of cases $[54,55]$. Our policy for leak management is to adopt the same technique as Ernst et al. [56]. We drain with a large internal drain of $12 \mathrm{~F}$. The drain is left in internal drainage and is controlled every month. As soon as the leak is healed and if there is no stenosis, the drain is withdrawn. If a stenosis is associated, it is dilated and the drain is left in place for 12 months.

Late biliary complications may appear months or years after transplantation. Their incidence is clearly associated to arterial thrombosis in $85 \%$ of cases [48]. Late biliary complication have some specific characteristics, and they are typically chronic problems that tends to persist or reccur after temporizing measures. Secondly, the localization of lesions is different from early complications. Because the mechanism (ischemic, cytomegalovirus infection, long cold ischemia exceeding $12 \mathrm{~h}$ ) causes 
diffuse lesions of the biliary tree, extensive intrahepatic, or hilar lesions may be found in that context more or less associated to sludge and desquamation debris in the lumen of bile ducts [57]. Debris and sludge can be managed percutaneously by flushing technique out of the biliary system or by associated lithotripsy necessitating a cholangioscopic equipment. These complications necessitate the extensive use of antibiotics during manipulations because of the risk of biliary infection and septic shock.

Diagnosis of late biliary complications carries some difficulties. Despite multiple stenosis, the biliary tree may not dilate causing false-negative US examinations. As a consequence, other modalities, such as MRCP, should be considered for the diagnosis [58]. Results of percutaneous or endoscopic drainage of hilar or diffuse intrahepatic stenosis shows that recurrence of stenosis is observed in more than $66 \%$ of cases [59, 60]. Factors that increase success rate are strictures developing within the first 3 months after transplantation, absence of hepatic artery thrombosis of cytomegalovirus infection, and of ductopenic rejection.

\section{Management of fluid collections}

Collections around the transplant are a common event in the postoperative period and may have multiple origins that may or not be associated. Collected ascitis, hematoma, and biliary leak are the most common causes. There is no definite argument on CT or ultrasound to differentiate these mechanisms. Percutaneous drainage is mandatory only is there are arguments for an infection of the collection. It should be attributed to biliary drainage when a fistula is proven on chemical analysis of the fluid.

\section{Conclusion}

Interventional radiology has progressed in all the fields of transplantation vascular and biliary complications. With the arrival of the new transplantation techniques, these complications are more frequent, and radiologists can expect to be solicited more often for their treatment.

\section{References}

1. Smith CM, Beasley GG, Cheng Y, Ormond DB (2000) Annual report of the US Organ Procurement and Transplantation Network 2000. OPTN/SR AR:191-237

2. Di Martini A, Kashyap R, Youk A, Rohal S, Fung J, Jain A (2000) Longterm survival after liver transplantation in 4000 consecutive patients at a single center. Liver Transpl 70:1335-1342

3. Shaw BW Jr, Wood RP, Stratta RJ, Pillen TJ, Langnas AN (1989) Stratifying the causes of death in liver transplant recipients: an approach to improving survival. Arch Surg 124:895900

4. Oh CK, Pelletier SJ, Sawyer RG et al. (2001) Uni- and multi-variate analysis of risk factors for early and late hepatic artery thrombosis after liver transplantation. Liver Transpl 71:767-772

5. Abbasoglu O, Levy M, Vodapally $\mathrm{M}$ et al. (1997) Hepatic artery stenosis after liver transplantation: incidence, presentation, treatment, and long-term outcome. Liver Transpl 1997:250-255

6. Stevens LH, Emond JC, Piper JB et al. (1992) Hepatic artery thrombosis in infants: a comparison of whole livers, reduced-size grafts, and grafts from living-related donors. Liver Transpl 53:396-399
7. Drazan K, Shaked A, Othoff K et al. (1996) Etiology and management of symptomatic adult hepatic artery thrombosis after orthotopic liver transplantation (OLT). Am Surg 62:237240

8. Stange BJ, Glanemann M, Nuessler NC, Settmacher U, Steinmuller T, Neuhaus P (2003) Hepatic artery thrombosis after adult liver transplantation. Liver Transpl 9:612-620

9. Nussler N, Settmacher U, Haase R, Stange B, Heise M, Neuhaus P (2003) Diagnosis and treatment of arterial steal syndromes in liver transplantation recipients. Liver Transpl 6:596602

10. Hall TR, McDiarmid SV, Grant EG, Boechat MI, Busuttil RW (1990) False-negative duplex Doppler studies in children with hepatic artery thrombosis after liver transplantation. Am J Roentgenol 154:573-575

11. Gunsar F, Rolando N, Pastacaldi S et al. (2003) Late hepatic artery thrombosis after orthotopic liver transplantation. Liver Transpl 9:605-611

12. Bhattacharjya S, Gunson BK, Mirza DF et al. (2001) Delayed hepatic artery thrombosis in adult orthotopic liver transplantation: a 12-year experience. Liver Transpl 71:1592-1596

13. Colonna JO II, Shaked A, Gomes AS et al. (1992) Biliary strictures complicating liver transplantation: incidence, pathogenesis, management, and outcome. Ann Surg 216:344-342
14. Garcia-Criado A, Gilabert R, Nicolau C et al. (2001) Early detection of hepatic artery thrombosis after liver transplantation by Doppler ultrasonography: prognostic implications. J Ultrasound Med 20:51-58

15. Dodd GD III, Memel DS, Zajko AB, Baron RL, Santaguida LA (1994) Hepatic artery stenosis and thrombosis in transplant recipients: Doppler diagnosis with resistive index and systolic acceleration time. Radiology 192:657661

16. Platt JF, Yutzy GG, Bude RO, Ellis JH, Rubin JM (1997) Use of Doppler sonography for revealing hepatic artery stenosis in liver transplant recipients. Am J Roentgenol 168:473-476

17. Sidhu P, Ellis S, Karani J, Ryan S (2002) Hepatic artery stenosis following liver transplantation: significance of the tardus parvus waveform and the role of microbubble contrast media in the detection of a focal stenosis. Clin Radiol 57:789-799

18. Figueras J, Busquets J, Dominguez J et al. (1995) Intra-arterial thrombolysis in the treatment of acute hepatic artery thrombosis after liver transplantation. Liver Transpl 59:1356-1357

19. Bjerkvik S, Vatne K, Mathisen O, Soreide O (1995) Percutaneous revascularization of postoperative hepatic artery thrombosis in a liver transplant. Liver Transpl 59:1746-1748 
20. Cotroneo AR, Stasi C di, Cina A et al. (2002) Stent placement in four patients with hepatic artery stenosis or thrombosis after liver transplantation. J Vasc Interv Radiol 13:619-623

21. Wozney P, Zajko AB, Bron K, Point S, Starzl TE (1986) Vascular complications after liver transplantation: a fiveyear experience. AJR 147:657-663

22. Denys AL, Qanadli SD, Durand F et al. (2002) Feasibility and effectiveness of using coronary stents in the treatment of hepatic artery stenoses after orthotopic liver transplantation: preliminary report. Am J Roentgenol 178:11751179

23. Abad J, Hidalgo E, Cantatero J et al. (1989) Hepatic artery anastomotic stenosis after transplantation: treatment with percutaneous balloon angioplasty. Radiology 171:661-662

24. Mondragon RS, Karani JB, Heaton ND et al. (1994) The use of percutaneous transluminal angioplasty in hepatic artery stenosis after transplantation. Liver Transpl 57:228-231

25. Orons PD, Zajko AB, Bron KM, Trecha GT, Selby RR, Fung JJ (1995) Hepatic artery angioplasty after liver transplantation: experience in 21 allografts. J Vasc Interv Radiol 6:523-529

26. Raby N, Karani J, Thomas S, O'Grady J, Williams R (1991) Stenoses of vascular anastomoses after hepatic transplantation: treatment with balloon angioplasty. Am J Roentgenol 157:167-171

27. Orons PD, Sheng R, Zajko AB (1995) Hepatic artery stenosis in liver transplant recipients: prevalence and cholangiographic appearance of associated biliary complications. Am J Roentgenol 165:1145-1149

28. Abad J, Hidalgo EG, Cantarero JM et al. (1989) Hepatic artery anastomotic stenosis after transplantation: treatment with percutaneous transluminal angioplasty. Radiology 171:661-662

29. Lerut J, Tzakis AG, Bron K et al. (1987) Complications of venous reconstruction in human orthotopic liver transplantation. Ann Surg 205:404-414

30. Malassagne B, Soubrane O, Dousset B, Legmann P, Houssin D (1998) Extrahepatic portal hypertension following liver transplantation: a rare but challenging problem. HPB Surg 10:357363

31. Buell JF, Funaki B, Cronin DC et al. (2002) Long-term venous complications after full-size and segmental pediatric liver transplantation. Ann Surg 236:658-666

32. Lee J, Ben-Ami T, Yousefzadeh D et al. (1996) Extrahepatic portal vein stenosis in recipients of living-donor allografts: Doppler sonography. Am J Roentgenol 167:85-90
33. Hamady M, Rela M, Sidhu PS (2002) Spontaneous resolution of a portal vein stenosis over a 21 -month period in a "split-liver" transplant: demonstration by colour Doppler ultrasound, catheter angiography and splenic pulp pressures. Eur Radiol 12:2280-2283

34. Rollins NK, Sheffield EG, Andrews WS (1992) Portal vein stenosis complicating liver transplantation in children: percutaneous transhepatic angioplasty. Radiology 182:731-734

35. Zajko AB, Sheng R, Bron K, Reyes J, Nour B, Tzakis A (1994) Percutaneous transluminal angioplasty of venous anastomotic stenoses complicating liver transplantation: intermediate-term results. J Vasc Interv Radiol 5:121-126

36. Funaki B, Rosenblum JD, Leef JA et al. (2000) Percutaneous treatment of portal venous stenosis in children and adolescents with segmental hepatic transplants: long-term results.

Radiology 215:147-151

37. Funaki B, Rosenblum JD, Leef JA, Hackworth CA, Szymski GX, Alonso EM (1997) Angioplasty treatment of portal vein stenosis in children with segmental liver transplants: mid-term results. Am J Roentgenol 169:551-554

38. Funaki B, Rosenblum JD, Leef JA et al. (1995) Portal vein stenosis in children with segmental liver transplants: treatment with percutaneous transhepatic venoplasty. Am J Roentgenol 165:161-165

39. Glanemann M, Settmacher U, Langrehr J et al. (2001) Portal vein angioplasty using a transjugular, intrahepatic approach for treatment of extrahepatic portal vein stenosis after liver transplantation. Transpl Int 14:1

40. Bhattacharjya T, Olliff SP, Bhattacharjya S, Mirza DF, McMaster P (2000) Percutaneous portal vein thrombolysis and endovascular stent for management of post-transplant portal venous conduit thrombosis. Liver Transpl 69:21952198

41. Baccarani U, Gasparini D, Risaliti A et al. (2001) Percutaneous mechanical fragmentation and stent placement for the treatment of early post-transplantation portal vein thrombosis. Liver Transpl 72:1572-1582

42. Orons PD, Hari AK, Zajko AB, Marsh JW (1997) Thrombolysis and endovascular stent placement for inferior vena caval thrombosis in a liver transplant recipient. Liver Transpl 64:1357-1361

43. Parrilla P, Acosta F, Bueno FS et al. (1999) Analysis of the complications of the piggy-back technique in 1112 liver transplants. Transpl Proc 31:2390-2391

44. Egawa H, Inomata Y, Uemoto S et al. (1997) Hepatic vein reconstruction in 152 living-related donor liver transplantation patients. Surgery 121:250-257
45. Sze DY, Semba CP, Razavi MK, Kee ST, Dake MD (1999) Endovascular treatment of hepatic venous outflow obstruction after piggy-back technique liver transplantation. Liver Transpl 68:446-449

46. Weeks SM, Gerber DA, Jaques PF et al. (2000) Primary Gianturco stent placement for inferior vena cava abnormalities following liver transplantation. J Vasc Interv Radiol 11:177-187

47. Verran DJ, Asfar SK, Ghent CN, Grant DR, Wall WJ (1997) Biliary reconstruction without T-tubes or stents in liver transplantation: report of 502 consecutive cases. Liver Transpl Surg 3:365-373

48. Greif F, Bronsther OL, Van Thiel DH et al. (1994) The incidence, timing, and management of biliary tract complications after orthotopic liver transplantation. Ann Surg 219:40-45

49. Reichert PR, Renz JF, Rosenthal P et al. (1998) Biliary complications of reduced-organ liver transplantation. Liver Transpl Surg 4:343-349

50. Scatton O, Meunier B, Cherqui D et al. (2001) Randomized trial of choledochostomy with or without a T-tube in orthotopic liver transplantation. Ann Surg 233:432-437

51. Rossi AF, Grosso C, Zanasi G et al. (1998) Long-term efficacy of endoscopic stenting in patients with stricture of the biliary anastomosis after orthotopic liver transplantation. Endoscopy 30:360-366

52. Mahajani RV, Cotler SJ, Uzer MF (2000) Efficacy of endoscopic management of anastomotic biliary strictures after hepatic transplantation. Endoscopy 32:943-949

53. Righi D, Cesarani F, Muraro E, Gazzera C, Salizzoni M, Gandini G (2002) Role of interventional radiology in the treatment of biliary strictures following orthotopic liver transplantation. Cardiovasc Interv Radiol 25:30-35

54. Morelli J, Mulcahy HE, Willner IR et al. (2001) Endoscopic treatment of post-liver transplantation biliary leaks with stent placement across the leak site. Gastrointest Endosc 54:471-475

55. Johnston TD, Gates R, Reddy KS, Nickl NJ, Ranjan D (2000) Non-operative management of bile leaks following liver transplantation. Clin Transpl 14:365-369

56. Ernst O, Sergent G, Mizrahi D, Delemazure O, L'Hermine C (1999) Biliary leaks: treatment by means of percutaneous transhepatic biliary drainage. Radiology 211:345-348 
57. Barton P, Maier A, Steininger R, Muhlbacher F, Lechner G (1995) Biliary sludge after liver transplantation. Part 1: Imaging findings and efficacy of various imaging procedures. Am J Roentgenol 164:859-864
58. Laghi A, Pavone P, Catalano C et al. (1999) MR cholangiography of late biliary complications after liver transplantation. Am J Roentgenol 172:1541-1546

59. O'Connor TP, Lewis WD, Jenkins RL (1995) Biliary tract complications after liver transplantation. Arch Surg 130:312-317

60. Ward EM, Kiely MJ, Maus TP, Wiesner RH, Krom RA (1990) Hilar biliary strictures after liver transplantation: cholangiography and percutaneous treatment. Radiology 177:259-263
61. Mondragon R, Karani J, Heaton N et al. (1994) The use of percutaneous transluminal balloon angioplasty in hepatic artery stenosis after transplantation. Liver Transpl 57:228-231 